Essays in Dynamic General Equilibrium Theory

Festschrift for David Cass

Series : Studies in Economic Theory, Vol. 20

Citanna, A.; Donaldson, J.; Polemarchakis, H.; Siconolfi, P.; Spear, S. (Eds.)

2005, X, 273 p., Hardcover

ISBN: 3-540-22267-7

\title{
Volatility and Job Creation in the Knowledge Economy
}

\author{
Graciela Chichilnisky and Olga Gorbachev
}

April 30, 2004 


\begin{abstract}
Sectors with increasing returns to scale have been shown to amplify business cycles exhibiting more volatility than others [13]. Our hypothesis is that this volatility could be a cause of the "jobless recovery" suggesting policies for employment generation. To test this hypothesis we introduce a general equilibrium model with involuntary unemployment. The economy has two sectors: one with increasing returns that are external to the firm and endogenously determined the knowledge sector - and the other with constant returns to scale. We define a measure of employment volatility, a 'labor beta' that is a relative of the 'beta' used in finance. A 'resolving' equation is derived from which it is proved that increasing return sectors exhibit more employment volatility then other sectors. The theoretical results are validated on US macro economic data of employment by industry (2-3 digits SIC codes) of the 1947-2001 period, showing that the highest 'labor betas' are in the service sectors with increasing returns to scale. Policy conclusions are provided to solve the puzzle of the 'jobless recovery', where small firms in the services industry play a key role. We conclude with policy recommendations on how to create jobs in the knowledge economy.
\end{abstract}




\section{Contents}

1 Volatility and Job Creation in the Knowledge Economy 2

1.1 Introduction . . . . . . . . . . . . . . . . . 2

1.2 General Equilibrium Model with External Economies of Scale and Involuntary Unemployment . . . . . . . . . . . . . . . . . 4

1.3 Volatility in the Knowledge Sectors . . . . . . . . . . . . . . 12

1.4 Empirical Issues . . . . . . . . . . . . . . . . . . . . . 14

1.5 The Puzzle of the Jobless Recovery . . . . . . . . . . . . . . . . 18

1.6 Conclusions and Policies for Job Creation . . . . . . . . . . . 22

1.7 Appendix . . . . . . . . . . . . . . . . 23 


\section{Chapter 1}

\section{Volatility and Job Creation in the Knowledge Economy}

\section{$1.1 \quad$ Introduction}

In a recent article [13] we showed that increasing returns to scale sectors amplify the business cycle: they grow faster than others during expansions, and contract faster during downturns. In this sense they exhibit more 'volatility' than other sectors $^{1}$. In this paper, we extend the earlier model to analyze volatility of employment. Our hypothesis is that this volatility could be a cause of the "jobless recovery" 2 suggesting policies for employment generation.

Chichilnisky-Gorbachev (2004) measured volatility using a new concept, a 'real beta', which is a statistical relative of the 'beta' used in financial markets, and measures real macro data on output rather than in stock prices. We used a general equilibrium model with two sectors, one with constant returns to scale (CRS) and the other with external increasing returns to scale (IRS), similar to that in Chichilnisky [9], [10] and [11]. In both sectors the firms are competitive, but the 'knowledge sector' ${ }^{3}$ has increasing returns to scale that are external

\footnotetext{
${ }^{1}$ The effect of the business cycle on IRS sectors has not been analyzed in the literature. Real Business Cycle models include IRS in order to generate cyclical productivity (see for example S. Basu and J. Fernald [3] and [4] for a review of the literature). In international trade, IRS is seen as determining the pattern and the factor content of trade (Krugman [23], [24], [25], [26], Panagariya [27], Antweiler et al. [1]). In growth literature, learning by doing leads to endogenous growth in the economy (see Arrow[2], Romer[30], and Rivera-Batiz and Romer[29]). In theoretical macrodynamic general equilibrium models, IRS may lead to unstable systems and may generate "vicious" and "virtuous" cycles in the economy (see Chichilnisky and Heal [14], and Heal [20], [19]).

${ }^{2}$ This is the second jobless recovery recorded in the US, the first was in 1990-1991.

${ }^{3}$ To identify "knowledge sectors" we used benchmarks from the World Knowledge Competitiveness Index introduced by Robert Huggins Associates, London, UK. The World Knowledge Competitiveness Index 2004 is an integrated and overall benchmark of the knowledge capacity, computed utilizing 19 knowledge economy benchmarks, including employment levels in the knowledge economy, patent registrations, $R \& D$ investment by the private and public sector, education expenditure, information and communication technology infrastructure, and access
} 
to the firm and are endogenously determined. The externalities arise from "learning by doing," analogous to Arrow (1962), and from the free transfer of skills from one firm to the other through job turnover or freely shared skills or R\&D. Increasing returns are endogenous because they depend on the output in the knowledge sector in equilibrium ${ }^{4}$. We showed that IRS sectors exhibit more volatility than other sectors, an outcome we tested empirically using US data ${ }^{5}$; as these sectors become a larger share of the economy their volatility increases economic uncertainty. These results are related to the 'virtuous and vicious' cycles in economies with increasing returns to scale that were developed earlier in Chichilnisky and Heal [14] and in Heal [20].

The model in Chichilnisky-Gorachev (2004) had full employment in equilibrium. Extending this model, we introduce here a general equilibrium model with involuntary unemployment and two sectors, one with external IRS and the other with CRS. The external IRS sectors or knowledge sectors are often characterized by having many small competitive firms. According to the Small Business Administration Office of Advocacy, small firms, defined as having 500 employees or less, represent 50 percent of all employment but generate about 60-80 percent of net jobs in the US [40]. Therefore, while IRS sectors are more volatile, small firms within IRS sectors create more jobs than they destroy and more jobs than larger firms, as pointed out by Chichilnisky (2004).

To achieve a meaningful representation of involuntary unemployment in a general equilibrium context, in the model presented here we postulate that labor supply is 'produced' as an increasing function of several variables rather than a constant endowment of time (24 hours) possessed by each individual from birth. The amount of labor supplied is constrained by the amount of physical energy, health, free time, skills, effort, and education a person possesses, which in turn relate to wages. An implication of this is that in a period of structural change, as labor skills become outdated, involuntary unemployment increases, an observation that has been made by the Federal Reserve Bank of New York in 2003 [18]. The formulation of our model of 'produced labor' supply has the same mathematical structure as the well-known Shapiro and Stiglitz efficiency wage model $[32]^{6}$; therefore, we do not provide a separate derivation of the labor market here, but use the Shapiro-Stiglitz model for this purpose as presented in

\footnotetext{
to private equity (www.hugginsassociates.com).

${ }^{4}$ Chipman (1970)[16] provides an excellent general equilibrium model with external economies of scale. The main difference with our model is in that his has only one factor of production and economies of scale are exogenously given, whereas here (and in Chichilnisky 1993, 1994, and 1998) there are two factors and the extent of IRS is endogenously determined in one sector of the economy- the other has constant returns.

${ }^{5}$ Our hypothesis is difficult to prove in complete generality, because the data of the last ten years is complex: industry classifications have changed and, as is well know, when using nominal data the increasing returns sectors (whose prices drop when production expands) are underrepresented in GDP. This observation is related to comments by William Baumol on productive and unproductive sectors, and to the November 2002 publication of Survey of Current Business, U.S. [35].

${ }^{6}$ The produced labor equation that we use here, see section 2.03 , is equivalent to the Nonshirking condition of Shapiro-Stiglitz, developed formally in the context of our model in the Appendix.
} 
the Appendix.

The article proceeds as follows: first we provide a general equilibrium model with involuntary unemployment and solve it analytically finding all prices, the level of unemployment, and production levels in equilibrium by means of a single 'resolving' equation; second we define the 'labor beta' measure of employment volatility for the different sectors of the economy, and prove formally that employment in external IRS sectors is more volatile than in other sectors; third, we provide details of the data used and validate the results on the observed 'labor betas' during the 1948-2001 periods; fourth, we discuss the jobless recovery in the context of this model. We show that small firms and the service sector play a crucial role and conclude with policy recommendations on how to create jobs in the knowledge economy.

\subsection{General Equilibrium Model with External Economies of Scale and Involuntary Unem- ployment}

\section{Internal and External Increasing Returns to Scale}

A firm or an industry has increasing returns to scale (IRS) when unit costs fall with increases in production ${ }^{7}$. Economies of scale are internal to the firm when a firm becomes more productive as its own size increases, i.e. more efficient, in utilizing its resources as is typical to firms with large fixed costs such as aerospace, airlines, and oil refineries ${ }^{8}$. In contrast, increasing returns to scale are external to the firm when the increased productivity comes about as a result of decreasing unit costs at the level of the industry as a whole. In the latter case, each firm could have constant unit costs as its production increases, and behave competitively ${ }^{9}$. Yet as the industry as a whole expands, positive externalities among the firms are created leading to increased productivity for all firms in the industry ${ }^{10}$. The free movement of skilled workers from one firm to another can have this effect, as a firm may benefit at no cost from training a worker received in another firm ${ }^{11}$. Equally, a firm can benefit from unspecific research and development innovations developed in other firms, which are accessible to it at little or no cost. These positive 'knowledge spillovers' often

\footnotetext{
${ }^{7}$ Sometimes they are defined by 'average' unit costs that decrease with production.

${ }^{8}$ This type of increasing returns can lead to monopolistic competition due to high entry costs.

${ }^{9}$ External IRS is consistent with small competitive firms; internal IRS depends instead on large size of firms which is typically inconsistent with competitive behavior.

${ }^{10}$ For example, in the period between 1990 and 2000, the expansion in output in the computer hardware industry led to yearly doubling of the computing power available per dollar, leading to an exponential increase in CPUs per dollar (a standardized measure of processing power) and to the corresponding rapid increase in demand and consumption of CPUs across the entire economy.

${ }^{11}$ Workers in the knowledge sectors move between firms more than others, on average every two years or less.
} 
originate from innovations generated during the course of production. As the new knowledge spreads to all the firms in the industry, total productivity in the industry increases and unit costs fall ${ }^{12}$.

\section{General Equilibrium with External Increasing Returns to Scale}

The economy produces and trades two goods $B$ and $I . B$ is a traditional constant returns to scale (CRS) industry, whereas $I$ is produced under external increasing returns to scale (IRS). Both goods are produced using two inputs, labor $L$ and capital $K$, and the firms in each industry are perfectly competitive. They minimize their costs given the market prices. Firms production functions are given as:

$$
B^{s}=L_{1}^{\alpha} K_{1}^{1-\alpha} \text { and } I^{s}=\gamma L_{2}^{\beta} K_{2}^{1-\beta}
$$

where $\alpha, \beta \in(0,1) . L_{1}, K_{1}$ are inputs in the $B$ sector, and $L_{2}, K_{2}$ are inputs in the $I$ sector. The total amount of labor and capital in the economy are $N$ and $K^{s}$ respectively. The parameter $\gamma$ in the production function for $I$ is taken as a constant by each firm within this industry. However, at the industry level, $\gamma$ is endogenously determined and increases with the output of $I$, i.e. $\gamma=\gamma\left(I^{s}\right)$. For example, $\gamma=I^{\sigma}, 0<\sigma<1$. In this case, when externalities are taken into account the production function for this sector is $I^{s}=L_{2}^{\frac{\beta}{1-\sigma}} K_{2}^{\frac{1-\beta}{1-\sigma}}$, although at the firm's level the technology that determines the firm's behavior is $I^{s}=\gamma L_{2}^{\beta} K_{2}^{1-\beta}$. Observe that $\sigma>1$ leads to negative marginal products, while $\sigma<0$ leads to decreasing returns. Therefore, when the sector $I$ has increasing returns, $\sigma$ satisfies $0<\sigma<1$, which we now assume ${ }^{13}$. Notice that returns to scale in the sector $I$ are endogenous because the parameter $\gamma=I^{\sigma}$ is unknown until the equilibrium value of $I$ is determined.

Prices for $I$ and $B$ are $p_{I}$ and $p_{B}$, respectively, and $I$ is a numeraire good, or $p_{I}=1$, then

$$
Y^{s}=I^{s}+p_{B} B^{s}
$$

By assumption each firm has external IRS so it forecasts a scale parameter $\gamma$ as exogenously given, and solves the cost minimization problem with first order conditions as:

$$
w=p_{B} \alpha\left(L_{1}\right)^{\alpha-1}\left(K_{1}\right)^{1-\alpha} \text { and } r=p_{B}(1-\alpha)\left(L_{1}\right)^{\alpha}\left(K_{1}\right)^{-\alpha} \text { in sector } B
$$

\footnotetext{
${ }^{12}$ Any industry that depends on knowledge or skilled labor could benefit from such knowledge spillovers and external economies of scale. In the growth literature related phenomena are known as 'learning by doing', a concept introduced by Arrow [2] and developed further by Romer [30] in a one sector growth model. 'Learning by doing' often refers to increasing returns that are internal to the firm. We focus instead on increasing returns that are external to the firm, endogenously determined and internal to one industry within a general equilibrium model with two goods and two factors, and in which a second sector has constant returns to scale.

${ }^{13}$ ¿From equation (1.19) the marginal product of labor is $M P L=$ $\frac{1}{1-\sigma}\left(\Phi\left(p_{B}\right)^{\frac{\sigma}{1-\sigma}}\right)\left(\frac{\partial \Phi}{\partial p_{B}}\right)\left(\frac{\partial p_{B}}{\partial L}\right)$. When $\sigma>1$ marginal product is negative. When $\sigma$ is less than or equal to 0 , the $I$ sector exhibits decreasing or constant returns to scale, and $0<\sigma<1$ is IRS.
} 


$$
w=\gamma \beta\left(L_{2}\right)^{\beta-1}\left(K_{2}\right)^{1-\beta} \text { and } r=\gamma(1-\beta)\left(L_{2}\right)^{\beta}\left(K_{2}\right)^{-\beta} \text { in sector } I
$$

We assume that both capital and labor markets are perfectly competitive, thus the factor prices paid in $B$ sector must equal that of $I$ sector. The $\gamma$ 's will be determined by equilibrium output and the $\gamma$ 's that the firms projected will be the ones obtained in general equilibrium ${ }^{14}$.

\section{'Produced' labor and involuntary unemployment in General Equilib- rium}

Our next task is to achieve a representation of involuntary unemployment in a general equilibrium context. To this end we postulate a 'produced' labor supply curve that is an increasing function of wages (see Figure 2 below). It is not the purpose of this article to provide an explicit derivation of the 'produced labor' supply curve; instead, we use as a model for this 'produced labor' supply the non-shirking condition that arises from the efficiency wage theory of Shapiro and Stiglitz [32] (see Figure 1), the connection between the two is developed below and in the Appendix, see Figure 1.

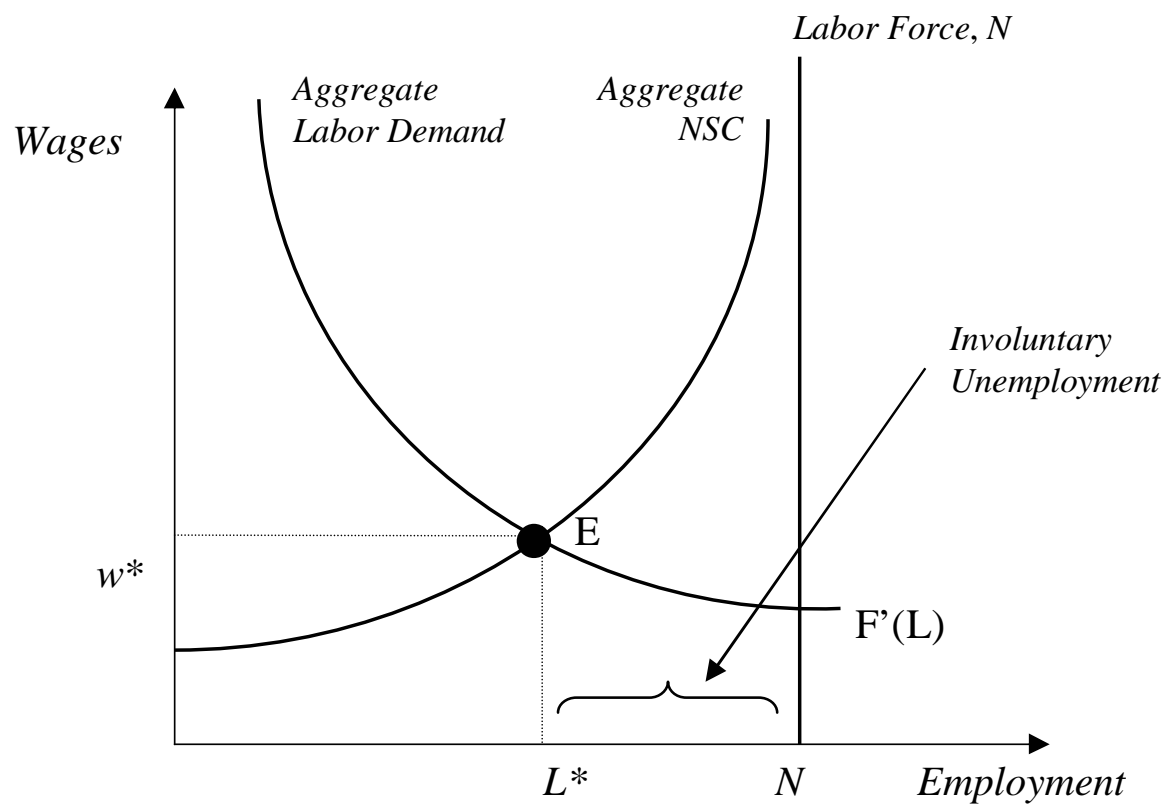

Figure 1: Labor Market Equilibrium in General Equilibrium Model with Involuntary Unemployment Asymmetric Information from Shapiro and Stiglitz (1984), see Appendix.

The 'produced' labor supply function is taken as exogenously given by workers (hence it is 'involuntary'). It represents not their willingness to work but

\footnotetext{
${ }^{14}$ This notion is similar to that of rational expectations assumptions for technology and production.
} 
rather the ability to do a certain job at a certain wage given for example the current skill or education level. In the Appendix, we consider a specific and familiar representation of this 'produced labor' function which delivers involuntary unemployment as in Shapiro-Stiglitz' efficiency wages article [32]. In that paper, the non-shirking condition (NSC) as illustrated in Figure 1 and derived in the Appendix ${ }^{15}$ acts as the equivalent to our 'produced' labor supply function. Shapiro-Stiglitz observe that in the environment characterized by imperfect information (in their case firms are unable to tell the actual effort level of their workers), firms are forced to pay a higher than market clearing wage in order to keep workers from shirking, hence the non-shirking condition and the resulting involuntary unemployment.

The 'produced labor' supply function increases with wages because workers are able to supply more labor at higher wages since acquisition of skills requires resources. For example, in the efficiency wage models, there is minimal threshold that workers must reach in order to be considered productive labor units (due for example to minimal income required to sustain persons' minimal health). As already mentioned, we do not derive explicitly this function, taking instead Shapiro-Stiglitz formulation as a foundation.

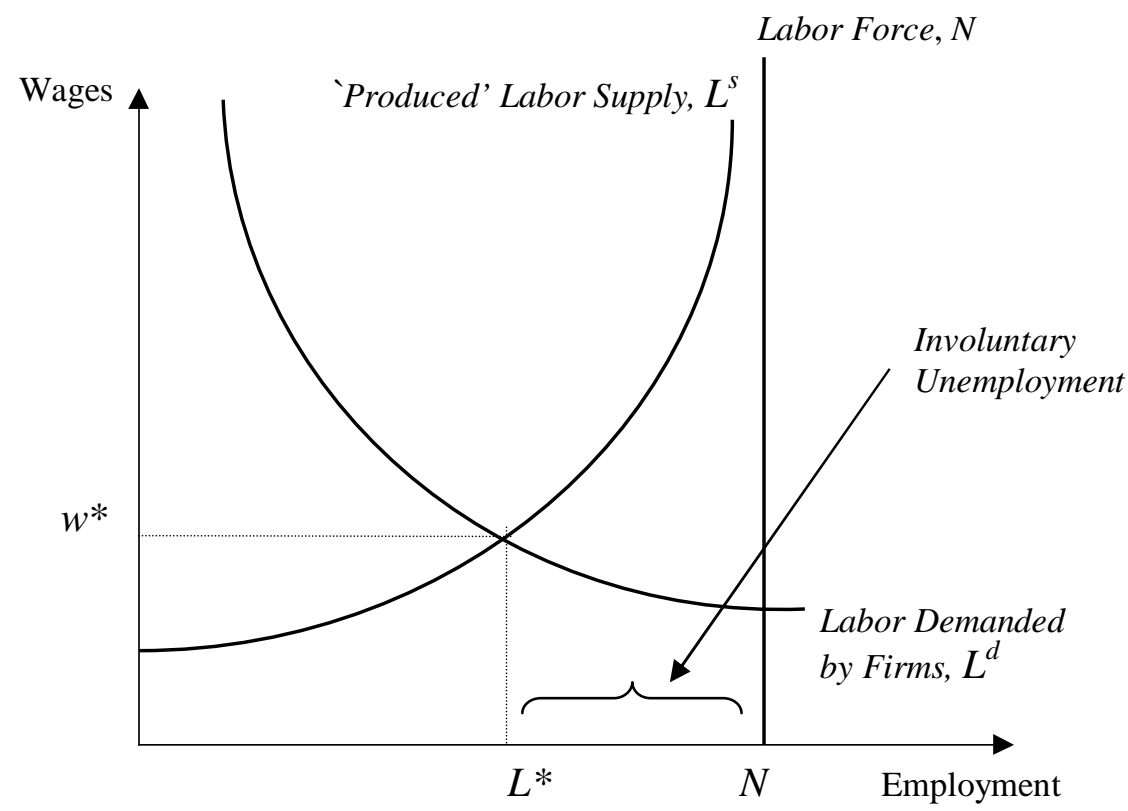

Figure 2: Labor Market Equilibrium in General Equilibrium Model with Involuntary Unemployment Arising from Produced Labor (analogous to Shapiro and Stiglitz model of 1984, see Figure 1)

${ }^{15}$ This figure is reproduced from Figure 2 of Shapiro-Stiglitz paper [32]. 
The concept of involuntary unemployment is illustrated in Figure $2^{16}$. The vertical line represents total potential labor force in the economy or the total number of individuals, $N$. Potential labor force, $N$, is different from the "produced' labor supply, which is a positively sloped curve, $L^{s}$, because as mentioned above it is an exogenously give function that depends on the current levels of workers' skills or education. $L^{s}$ is a function of wages, $w$, and prices, $p_{B}$, or $L^{s}=L^{s}\left(w, p_{B}\right)$. Labor demand, $L^{d}$, is a decreasing function of wage and is derived from firms' cost minimization problem or after solving for $L$ in equation (1.3).

In equilibrium, due to the shape of labor supply curve, there will exist involuntary unemployment, represented by the difference in labor employed $L^{*}$ and potential labor supply, $N$. Unemployment, $\left(N-L^{*}\right)$, is involuntary since there are workers who are willing to work at a lower wage but because they cannot credibly promise to do the job since they do not have the requiredskills. Thus, they will not be hired. According to Shapiro and Stiglitz' model, unemployment is involuntary because workers who are willing to work at a lower than equilibrium wage cannot make a credible promise to exert effort or not to shirk.

\section{Resolving the General Equilibrium Model}

This section draws on the results of Chichilnisky [9] and Chichilnisky-Gorbachev [13] to solve our general equilibrium model with involuntary unemployment. To solve this model, there are four prices to be determined: the goods prices $p_{B}^{*}$ and $p_{I}^{*}$, and the two factor prices, wages and return on capital, $w^{*}$ and $r^{*}$. The quantities to be determined in an equilibrium are: the use of factors in each sector $K_{1}^{*} K_{2}^{*} L_{1}^{*} L_{2}^{*}$, the outputs of the two goods $B^{s *}$ and $I^{s *}$, the parameter $\gamma^{*}$ determining the external economies of scale in $I$, and the demand for goods $B$ and $I, B^{d *}$ and $I^{d *}$. Thus the model has 13 endogenous variables to be computed, $p_{B}^{*}, p_{I}^{*}, w^{*}, r^{*}, K_{1}^{*} K_{2}^{*} L_{1}^{*} L_{2}^{*}, B^{s *}, I^{s *}, \gamma^{*}, B^{d *}$ and $I^{d *}$.

We solve the model by finding an explicit function of a single variable, $p_{B}$, (called a 'resolving' equation) and 5 exogenously given parameters of the economy: $\alpha, \beta, \sigma, N$ and $K^{s}$. To obtain the resolving equation we write the market clearing condition in the $I$ market, demand equals supply, and find a way to express it as a function of only one variable: $p_{B}$. Solving this equation gives the equilibrium value of $p_{B}^{*}$, from which all other endogenous variables listed above can be found ${ }^{17}$. Since the model has constant returns to scale at the level of the firms ${ }^{18}$, we derive the equilibrium relations between supplies and prices from the marginal conditions, clearing of labor market and full employment of capital.

\footnotetext{
${ }^{16}$ Notice that Figure 2 is a special case of Figure 1.

${ }^{17}$ Notice that we have not defined supply behavior outside of an equilibrium; in particular, there is no information for carrying out stability analysis.

${ }^{18}$ As mentioned in the text, individual firms in both sectors of the economy exhibit CRS. Firms that belong to external IRS sector don't know that positive externalities are generated by their production or hiring decisions. Thus, firms in external IRS sectors, take $\gamma$ of (1.1) equation as given.
} 
For simplicity ${ }^{19}$, demand functions for $B$ given as a function of initial endowments and prices:

$$
B^{d}=B^{d}\left(N, K^{s}, p_{B}\right)
$$

In equilibrium all markets clear, or:

$$
\begin{gathered}
B^{s *}=B^{d *}+X_{B}^{*}(B \text { market clears }) \\
I^{s *}=I^{d *}+X_{I}^{*}(I \text { market clears })
\end{gathered}
$$

where $X_{B}^{*}$ and $X_{I}^{*}$ are equilibrium levels of net exports in $B$ and $I$ sectors respectively. We assume $X_{I}^{*}=0$ and $X_{B}^{*}=0$ but the results are true for any given $X_{I}^{*}$ and $X_{B}^{*}$.

$$
\begin{gathered}
p_{B}^{*} B^{s *}+I^{s *}=w^{*} L^{*}+r^{*} K^{*} \text { (zero profits) } \\
K^{*}=K^{s}=K_{1}^{*}+K_{2}^{*} \text { (capital market clears) } \\
L^{*}=L^{s}=L^{d}=L_{1}^{*}+L_{2}^{*} \text { ('involuntary' labor market clears) }
\end{gathered}
$$

Notice however that labor market clears in the sense that 'produced' labor supply is equal to labor demand. But since 'produced' labor supply is given by $L^{s}=L^{s}\left(w, p_{B}\right)$ and is different from the potential labor supply, $N$, the labor market is characterized by the existence of involuntary unemployment, since $N>L^{*}$, as shown in Figure 1. Workers without a job are willing to work at a wage below $w^{*}$ but will not be hired because below the clearing wage, the $L^{s}$ produced by these workers is below firm's requirement since workers are not as educated or not as healthy to do the needed job.

We can characterize 'involuntary' labor market equilibrium in a more explicit way. Denoting $l_{1}=\frac{L_{1}}{K_{1}}$ and $l_{2}=\frac{L_{2}}{K_{2}}$, we can rewrite marginal conditions (1.3) as:

$$
\begin{gathered}
w=\alpha\left(l_{1}\right)^{\alpha-1} p_{B} \text { and } r=(1-\alpha)\left(l_{1}\right)^{\alpha} p_{B} \\
w=\gamma \beta\left(l_{2}\right)^{\beta-1} \text { and } r=\gamma(1-\beta)\left(l_{2}\right)^{\beta}
\end{gathered}
$$

Indicating logarithms with the symbol " " the four equations above can be rewritten as:

$$
\begin{gathered}
\widetilde{w}=(\alpha-1) \widetilde{l_{1}}+\widetilde{\alpha}+\widetilde{p_{B}} \text { and } \widetilde{r}=\alpha \widetilde{l_{1}}+\widetilde{(1-\alpha)}+\widetilde{p_{B}} \\
\widetilde{w}=(\beta-1) \widetilde{l_{2}}+\widetilde{\beta}+\widetilde{\gamma} \text { and } \widetilde{r}=\beta \widetilde{\beta} \tilde{l}_{2}+\widetilde{(1-\beta)}+\widetilde{\gamma}
\end{gathered}
$$

so that $(\alpha-1) \widetilde{l_{1}}-(\beta-1) \widetilde{l_{2}}=\widetilde{\beta}-\widetilde{\alpha}-\widetilde{p_{B}}+\widetilde{\gamma}$

and $\alpha \widetilde{l_{1}}-\beta \widetilde{l_{2}}=(\widetilde{1-\beta})-\left(\widetilde{1-\alpha)}-\widetilde{p_{B}}+\widetilde{\gamma}\right.$.

Solving for $\widetilde{l_{1}}$ and $\widetilde{l_{2}}$ we obtain:

$$
\widetilde{l_{1}}=\frac{\left(\widetilde{\beta}-\widetilde{p_{B}}-\widetilde{\alpha}+\widetilde{\gamma}\right)(-\beta)-(1-\beta)\left[(\widetilde{1-\beta})-\widetilde{p_{B}}-(\widetilde{1-\alpha})+\widetilde{\gamma}\right]}{[\beta-\alpha]}
$$

\footnotetext{
${ }^{19}$ The results of the model do not depend on the demand specification. But in the Appendix, we solve for a specific demand function.
} 


$$
\widetilde{l_{2}}=\frac{(\alpha-1)\left[\widetilde{(1-\beta)}-\widetilde{p_{B}}-(\widetilde{1-\alpha})+\widetilde{\gamma}\right]-\alpha\left(\widetilde{\beta}-\widetilde{p_{B}}-\widetilde{\alpha}+\widetilde{\gamma}\right)}{[\beta-\alpha]}
$$

or

$$
\widetilde{l_{1}}=\frac{\widetilde{p_{B}}}{(\beta-\alpha)}+A \text { and } \widetilde{l_{2}}=\frac{\widetilde{p_{B}}}{(\beta-\alpha)}+B
$$

where $A$ and $B$ such that:

$$
\begin{gathered}
A=\frac{(\widetilde{\beta}-\widetilde{\alpha})(-\beta)-(1-\beta)[\widetilde{(1-\beta})-(\widetilde{1-\alpha})]-\widetilde{\gamma}}{[\beta-\alpha]} \\
B=\frac{(\alpha-1)[(\widetilde{1-\beta})-(\widetilde{1-\alpha})]-\alpha[\widetilde{\beta}-\widetilde{\alpha}]-\widetilde{\gamma}}{[\beta-\alpha]}
\end{gathered}
$$

$A$ and $B$ are constants since $\widetilde{\gamma}$ is taken as a constant by each individual firm. Also observe that $A>0$ and $B<0$ if $\beta<\alpha$. Therefore,

$$
l_{1}=e^{A} p_{B}^{\frac{1}{\beta-\alpha}} \text { and } l_{2}=e^{B} p_{B}^{\frac{1}{\beta-\alpha}}
$$

Using (1.9), marginal conditions can be written as:

$$
w=\alpha e^{A(\alpha-1)} p_{B}^{\frac{\beta-1}{\beta-\alpha}} \text { and } r=(1-\alpha) e^{A \alpha} p_{B}^{\frac{\beta}{\beta-\alpha}}
$$

Substituting (1.10) into $L^{s}=L^{s}\left(w, p_{B}\right)$, we can rewrite $L^{s}$ as a function of $p_{B}$ alone, or:

$$
L^{s}=L^{s}\left(p_{B}\right)
$$

'Involuntary' labor market clears, or:

$$
L^{s}\left(p_{B}\right)=L^{d}\left(p_{B}\right)=L^{* 20}
$$

Since $l_{2}=\frac{L^{*}-L_{1}}{K^{S}-K_{1}}$ or $L_{1}=L^{*}-l_{2}\left(K^{S}-K_{1}\right)$. At same time, $l_{1}=\frac{L_{1}}{K_{1}}$, so that $L^{*}-l_{2}\left(K^{S}-K_{1}\right)=l_{1} K_{1}$.

The quantity of $K$ and $L$ demanded in the $B$ sector are:

$$
K_{1}=\frac{L^{*}-l_{2} K^{S}}{\left(l_{1}-l_{2}\right)} \text { and } L_{1}=\frac{l_{1}}{\left(l_{1}-l_{2}\right)}\left(L^{*}-l_{2} K^{S}\right)
$$

From (1.9), (1.12) and (1.13) $K$ and $L$ are functions of a single variable $p_{B}$ :

$$
\begin{aligned}
L_{1} & =\frac{e^{A} L^{*}}{\left(e^{A}-e^{B}\right)}-\frac{e^{A} e^{B} K^{s} p_{B}^{\frac{1}{\beta-\alpha}}}{\left(e^{A}-e^{B}\right)}=L_{1}\left(p_{B}\right) \\
K_{1} & =\frac{L^{*} p_{B}^{\frac{1}{\alpha-\beta}}}{\left(e^{A}-e^{B}\right)}-\frac{e^{B} K^{s}}{\left(e^{A}-e^{B}\right)}=K_{1}\left(p_{B}\right)
\end{aligned}
$$

\footnotetext{
${ }^{20}$ Notice that this condition is different from the one used in Chichilnisky-Gorbachev paper [13]. Previous paper had full employment of labor and capital and therefore no involuntary unemployment. Here due to the 'produced labor' function (1.12) there is involuntary unemployment.
} 
Equations (1.14) and (1.15) hold for any level of $\gamma$. In particular, taking $\gamma=1$, we denote production of $B$ and $I$ as $\Psi\left(p_{B}\right)$ and $\Phi\left(p_{B}\right)$ respectively. Therefore, from (1.1), (1.14) and (1.15) we obtain the equilibrium level of output as a function of equilibrium price $p_{B}^{*}$ :

$$
\begin{gathered}
B^{s *}=\left[\frac{e^{A} L^{*}}{\left(e^{A}-e^{B}\right)}-\frac{e^{A} e^{B} K^{s} p_{B}^{\frac{1}{\beta-\alpha}}}{\left(e^{A}-e^{B}\right)}\right]^{\alpha}\left[\frac{L^{*} p_{B}^{\frac{1}{\alpha-\beta}}}{\left(e^{A}-e^{B}\right)}-\frac{e^{B} K^{s}}{\left(e^{A}-e^{B}\right)}\right]^{1-\alpha}=\Psi\left(p_{B}^{*}\right) \\
I^{s *}=\gamma\left[L^{*}-\frac{e^{A} L^{*}}{\left(e^{A}-e^{B}\right)}-\frac{e^{A} e^{B} K^{s} p_{B}^{\frac{1}{\beta-\alpha}}}{\left(e^{A}-e^{B}\right)}\right]^{\beta}\left[K^{s}-\frac{L^{*} p_{B}^{\frac{1}{\alpha-\beta}}}{\left(e^{A}-e^{B}\right)}-\frac{e^{B} K^{s}}{\left(e^{A}-e^{B}\right)}\right]^{1-\beta} \\
=\gamma\left(p_{B}^{*}\right)
\end{gathered}
$$

For industry $I,(1.16)$, does not express output as an explicit function of equilibrium prices alone as we wished, because $\gamma=\gamma(I)$, and $I=I\left(\gamma, p_{B}\right)$. In order to obtain output as explicit functions of equilibrium prices we must therefore find out the equilibrium value of the scale parameter $\gamma^{*}$. This is an additional "fixed point" problem, since $\gamma$ depends on $I$, while $I$ depends on $\gamma$. We solve this as follows.

The industry $I$ has increasing returns which are external to the firms in this industry, and the parameter $\gamma$ increases with the level of output of $I$. We postulated that

$$
\gamma=I^{\sigma}, \text { where } 0<\sigma<1 \text {. }
$$

At an equilibrium, equations (1.16) and (1.17) must be simultaneously satisfied, i.e. $\gamma=\left[\gamma \Phi\left(p_{B}\right)\right]^{\sigma}=\gamma^{\sigma} \Phi\left(p_{B}\right)^{\sigma}$ or, $\gamma^{1-\sigma}=\Phi\left(p_{B}\right)^{\sigma}$.

Thus,

$$
\gamma=\Phi\left(p_{B}\right)^{\frac{\sigma}{(1-\sigma)}}
$$

Therefore at an equilibrium from (1.16) and (1.18) we obtain a relation between the outputs of $I$ and $p_{B}$ :

$$
I^{s *}\left(p_{B}\right)=\Phi\left(p_{B}^{*}\right)^{\frac{1}{(1-\sigma)}}
$$

so that

$$
I^{S *}\left(p_{B}\right)=\left\{\begin{array}{l}
\left\{L^{*}-\frac{e^{A} L^{*}}{\left(e^{A}-e^{B}\right)}-\frac{e^{A} e^{B} K^{s} p_{B}^{\frac{1}{\beta-\alpha}}}{\left(e^{A}-e^{B}\right)}\right\}^{\frac{\beta}{1-\sigma}} \\
*\left\{K^{s}-\frac{L^{*} p_{B}^{\frac{1}{\alpha-\beta}}}{\left(e^{A}-e^{B}\right)}-\frac{e^{B} K^{s}}{\left(e^{A}-e^{B}\right)}\right\}^{\frac{1-\beta}{1-\sigma}}
\end{array}\right\}
$$

\section{The Resolving Equation $F\left(p_{B}\right)$}

We can now give explicitly the 'resolving' equation for the model, denoted $F\left(p_{B}\right)$ below: 


$$
F\left(p_{B}\right)=I^{d *}\left(p_{B}\right)-I^{s *}\left(p_{B}\right)=I^{d *}\left(p_{B}\right)-\Phi\left(p_{B}^{*}\right)^{\frac{1}{(1-\sigma)}}=0
$$

or,

$$
F\left(p_{B}=I^{d *}-\left\{\begin{array}{l}
\left\{L^{*}-\frac{e^{A} L^{*}}{\left(e^{A}-e^{B}\right)}-\frac{e^{A} e^{B} K^{s} p_{B}^{\frac{1}{\beta-\alpha}}}{\left(e^{A}-e^{B}\right)}\right\}^{\frac{\beta}{1-\sigma}} \\
*\left\{K^{s}-\frac{L^{*} p_{B}^{\frac{1}{\alpha-\beta}}}{\left(e^{A}-e^{B}\right)}-\frac{e^{B} K^{s}}{\left(e^{A}-e^{B}\right)}\right\}^{\frac{1-\beta}{1-\sigma}}
\end{array}\right\}=0\right.
$$

where from (1.10) and (1.4), $I^{d *}\left(p_{B}\right)$ is a function of $p_{B}$ alone:

$I^{d *}\left(p_{B}\right)=\left(\alpha e^{A(\alpha-1)} p_{B}^{\frac{\beta-1}{\beta-\alpha}}\right) L^{*}+\left((1-\alpha) e^{A \alpha} p_{B}^{\frac{\beta}{\beta-\alpha}}\right) K^{s}-p_{B}^{*} B^{d *}\left(p_{B}^{*}\right)$

Solving the equation $F\left(p_{B}\right)=0$, gives an equilibrium value of $p_{B}^{*}$ from which all equilibrium values of other variables $\left(K_{1}^{*}, K_{2}^{*} L_{1}^{*} L_{2}^{*}, w^{*}, r^{*}, B^{s *}, I^{s *}, B^{d *}, I^{d *}\right.$, $\left.\gamma^{*}\right)$ can be computed. The model is thus solved.

\subsection{Volatility in the Knowledge Sectors}

Our hypothesis is that the level of employment in the increasing returns to scale sectors (IRS) is more volatile than that of other sectors, in the sense that employment increases more in IRS sectors than in the rest of the economy during upturns; during downturns, it contracts more than in the rest of the economy. To test this hypothesis we introduce a measure of volatility of employment, similar to that used in our previous paper, and explore its behavior in a general equilibrium model with involuntary unemployment.

\section{Volatility Index: the 'labor beta'}

We define an index to measure volatility that is independent of the scale of the variables, denoted 'labor beta'. This is a statistical relative of the financial markets concept of 'beta' that is frequently used to measure volatility of stock prices:

$$
\beta=\frac{\operatorname{Cov}(X, Y)}{\operatorname{Var}(Y)}
$$

Here $X$ and $Y$ are employment levels rather than stock prices, $X$ representing employment in a sector and $Y$, aggregate employment. $\beta_{I R S}$ denotes the 'labor beta' associated with the increasing returns sector and $\beta_{C R S}$ that of constant returns to scale sector. Our hypothesis can now be stated as:

Hypothesis: $\quad \beta_{I R S}>\beta_{C R S}$. 


\section{Volatility: the effects of shocks on employment across sectors}

To study employment volatility we assume that there are random shocks to the 'fundamentals' of the model (technologies, preferences, demand, initial endowments of capital and labor). The fundamentals thus vary from period to period, although there are no intertemporal links between one period or another. The equilibrium value of $p_{B}^{*}$ varies with the fundamentals producing fluctuations in all equilibrium values of the model, and in particular in equilibrium levels of labor utilized by each sector: $L_{1}^{*}$ and $L_{2}^{*}$. Using the general equilibrium model, we study the attendant variations in $L_{1}^{*}$ and $L_{2}^{*}$, exploring the extent to which employment in sector $I$ is systematically more volatile than that in sector $B$.

From the 'resolving' equation, $F\left(p_{B}\right)$, we know how all the variables of the model fluctuate with $p_{B}^{*}$. Expressing labor demand for each sector as a function of output of that sector will allow us to use the main result of the "Volatility in the Knowledge Economy" $\operatorname{article}^{21}$ to prove that employment volatility of the IRS sector $I$ is larger than that of CRS sector $B$. Solving the firm's cost minimization problem $L_{1}$ and $L_{2}$ can be expressed as functions of factor prices and total output of their respective sectors, or:

$$
L_{1}=B\left(\frac{(1-\alpha) r}{\alpha w}\right)^{\alpha} \text { and } L_{2}=I\left(\frac{(1-\beta) r}{\beta w}\right)^{\beta}
$$

From (1.10), (1.16), and (1.19), the above expressions are functions of a single parameter $p_{B}$ found after solving the 'resolving' equation $F\left(p_{B}\right)$ (1.21), or

$$
L_{1}\left(p_{B}\right)=\Psi\left(p_{B}\right)\left(\frac{(1-\alpha) r\left(p_{B}\right)}{\alpha w\left(p_{B}\right)}\right)^{\alpha}
$$

and

$$
L_{2}\left(p_{B}\right)=\Phi\left(p_{B}\right)^{\frac{1}{(1-\sigma)}}\left(\frac{(1-\beta) r\left(p_{B}\right)}{\beta w\left(p_{B}\right)}\right)^{\beta}
$$

Proposition 1 Employment volatility in the increasing returns to scale sector $I$ is larger than that in the constant returns to scale sector B, i.e. the 'labor beta' of external IRS sector, $\beta_{I R S}$, is larger than the 'labor beta' of the CRS sector, $\beta_{C R S}$, namely $\beta_{I R S}>\beta_{C R S}$, when increasing returns are large enough, i.e. $0<\sigma<1$ and $\sigma \sim 1$.

Proof. We aim to prove the following inequality:

$$
\beta_{I R S}=\frac{\operatorname{Cov}\left(L_{2 t}^{*}, L_{t}^{*}\right)}{\operatorname{Var}\left(L_{t}^{*}\right)}>\beta_{C R S}=\frac{\operatorname{Cov}\left(L_{1 t}^{*}, L_{t}^{*}\right)}{\operatorname{Var}\left(L_{t}^{*}\right)}
$$

where $L_{t}^{*}=L_{1 t}+L_{2 t}$. Because the denominators of (1.26) are equal and positive, we can restate it as:

$$
\operatorname{Cov}\left(L_{2 t}^{*}, L_{t}^{*}\right)>\operatorname{Cov}\left(L_{1 t}^{*}, L_{t}^{*}\right)
$$

\footnotetext{
${ }^{21}$ Specifically, in that article we showed that as $\sigma \rightarrow 1, \beta_{I R S}>\beta_{C R S}$, or that output of the IRS sector is more volatile than that of the CRS sector.
} 
Rewriting (1.27):

$$
\sum_{t=1}^{T}\left(L_{2 t}-\overline{L_{2}}\right)\left(L_{t}^{*}-\overline{L^{*}}\right)>\sum_{t=1}^{T}\left(L_{1 t}-\overline{L_{1}}\right)\left(L_{t}^{*}-\overline{L^{*}}\right)
$$

where $\overline{L_{1 t}}, \overline{L_{2 t}}$ and $\overline{L_{t}^{*}}$ denote time averages: $\overline{L_{1}}=\frac{1}{T} \sum_{t=1}^{T}\left(L_{1 t}\right)$.

Rearranging the terms (1.27) becomes:

$$
\sum_{t=1}^{T}\left\{\left[\left(L_{2 t}-\overline{L_{2}}\right)-\left(L_{1 t}-\overline{L_{1}}\right)\right]\left(L_{t}^{*}-\overline{L^{*}}\right)\right\}>0
$$

Substituting for $L_{t}^{*}$ and $\overline{L^{*} \text { : }}$

$$
\begin{gathered}
\sum_{t=1}^{T}\left\{\left[\left(L_{2 t}-\overline{L_{2}}\right)-\left(L_{1 t}-\overline{L_{1}}\right)\right]\left[\left(L_{1 t}+L_{2 t}\right)-\left(\overline{\left.L_{1}+L_{2}\right)}\right]\right\}>0,\right. \text { or } \\
\sum_{t=1}^{T}\left\{L_{2 t}^{2}-L_{1 t}^{2}\right\}+T\left\{\left(\overline{\left(L_{1}\right.}\right)^{2}-\left(\overline{L_{2}}\right)^{2}\right\}>0
\end{gathered}
$$

From (1.21) and (1.24) we obtain:

$$
\begin{aligned}
& \sum_{t=1}^{T}\left\{\Phi\left(p_{B}\right)^{\frac{2}{(1-\sigma)}}\left(\frac{(1-\beta) r\left(p_{B}\right)}{\beta w\left(p_{B}\right)}\right)^{2 \beta}-\Psi\left(p_{B}\right)^{2}\left(\frac{(1-\alpha) r\left(p_{B}\right)}{\alpha w\left(p_{B}\right)}\right)^{2 \alpha}\right\} \\
& +T\left\{\overline{\left(L_{1}\right)^{2}}-\left(\overline{L_{2}}\right)^{2}\right\}>0
\end{aligned}
$$

For every $t$, as $\sigma \rightarrow 1$ and $\Phi_{t}\left(p_{B}\right)>1$, the inequality (1.29) is satisfied since the first term $\left(\Phi_{t}\left(p_{B}\right)^{\frac{2}{(1-\sigma)}}\right)$ dominates the equation. It follows therefore, that $\beta_{I R S}>\beta_{C R S}$.

\subsection{Empirical Issues}

In this section we validate empirically our theoretical result that employment in IRS sectors is more volatile in CRS sectors.

\section{Data Sources and Structure}

We use employment data provided by the Survey of Current Business $(S C B)^{22}$, prepared by the U.S. Department of Commerce, Bureau of Economic Analysis (BEA), in Washington, DC, utilizing 'Full Time and Part Time Employees' by industry in thousands for 1948-2001 period (2-3 digit Standard Industry Codes (SIC) $)^{23}$. There is a "break" in the time series of this data due to the SIC reclassification. Thus, 1948-1987 data uses 1972 SIC classification, whereas 1987-2001 uses 1987 SIC classification (the estimates of 1977-1987 have not been adjusted to 1987 SIC code due to "lack of adequate data" according to BEA May 2003 publication [34]).

\footnotetext{
${ }^{22}$ Monthly government publications to be found in www.bea.gov.

${ }^{23}$ Detailed data series are available at the BEA webpage:

http://www.bea.gov/bea/dn2/gpo.htm
} 


\section{IRS and Traditional Industries}

We reviewed the literature and adopted its findings about IRS sectors, ${ }^{24}$ as in our 2004 article [13]. We also used a simple correlation between quantities produced and prices charged on the level of industry to identify IRS sectors (the sector is considered to exhibit IRS if correlation is negative ${ }^{25}$. Figure 3 lists the IRS sectors identified by the empirical literature, showing in each case the respective sources. From the list in Figure 3 we separated out industries that as in the previous paper, we characterize as having internal IRS due to high fixed $\operatorname{costs}^{26}$. We were left with 8 industries with external economies of scale, which we compared with some of the World Knowledge Competitiveness Index benchmarks (see footnote 2 for details):

1. Credit agencies other than banks (SIC 61)

2. Electronic equipment and instruments $(36,38)$

3. Machinery, except electrical (35)

4. Retail Trade (52-59)

5. Security and commodity brokers (62)

6. Services (70, 72-73, 75-76, 78-89)

7. Telephone and telegraph $(481,482,489)$

8. Wholesale Trade $(50,51)$.

\section{Employment in increasing returns sectors is more volatile}

Total employment's 'labor beta', by definition, is equal to one. Figure 4 provides 'labor betas' for industries with external economies of scale and for some traditional industries. What is immediately apparent from Figure 4 is that 'labor betas' for IRS industries are on average larger than that of traditional industries, and that the volatility in the service sector drives the results.

In addition, breaking the data into three sub-periods, 1947-1987 and 19882001 (chosen arbitrarily at the break of the series and to be consistent with our previous paper) provides another interesting view of the data. The 'labor betas'

\footnotetext{
${ }^{24}$ A study by S. Basu and J. Fernald [3] of US private economy (2-3 SIC) find IRS in: 1. Metal Mining, 2. Construction, 3. Furniture, 4. Paper, 5. Primary Metals, 6. Fabricated Metals, 7. Electrical Machinery, 8. Motor Vehicles, 9. Transportation, 10. Communication, 11. Electric Utilities, 12. Wholesale and Retail, 13. Services (various).

Work by W. Antweiler and D. Trefler [1] examine 27 manufacturing and 7 nonmanufacturing industries (no services) for 71 countries over 1972-1992 period and identified 11 industries with increasing returns: 1. Petroleum and Coal Products, 2. Pharmaceuticals, 3. Electric and Electronic Machinery, 4. Petroleum Refineries, 5. Iron and Steel Basic Industries, 6. Instruments, 7. Non-Electric Machinery, 8. Forestry, 9. Livestock, 10. Crude Petroleum and Natural Gas, 11. Coal Mining. Their general equilibrium model estimates scale for these industries in the rage of 1.10 to 1.20 .

Paul and Siegel [28] find that scale economies are prevalent in US manufacturing. In particular, this study finds evidence of external economies of scale due to supply-side agglomeration.

${ }^{25}$ Specifically, we used chain-type quantity index for GDP by industry and chain-type price index for GDP by industry from BEA for our correlation computations. Detailed data files can be downloaded at: http://www.bea.gov/bea/dn2/gpo.htm.

${ }^{26} \mathrm{It}$ is important to carefully study the structure of each industry before characterizing it as having internal or external IRS. This is a subject of our further research in this area.
} 


\begin{tabular}{|l|c|}
\hline & Identification \\
\hline Agriculture, forestry, and fishing & $\mathrm{AT}$ \\
Credit agencies other than banks & $\mathrm{corr}=<0$ \\
Coal mining & $\mathrm{AT}$ \\
Communications & $\mathrm{BF}$ \\
Construction & $\mathrm{BF}$ \\
Electronic equipment and instruments & $\mathrm{BF}, \mathrm{AT}$ \\
Fabricated metal products & $\mathrm{BF}$ \\
Furniture and fixtures & $\mathrm{BF}$ \\
Machinery, except electrical & $\mathrm{AT}$ \\
Metal mining & $\mathrm{BF}$ \\
Motor vehicles and equipment & $\mathrm{BF}$ \\
Oil and gas extraction & $\mathrm{AT}$ \\
Paper and allied products & $\mathrm{BF}$ \\
Petroleum and coal products & $\mathrm{AT}$ \\
Primary metal industries & $\mathrm{BF}$ \\
Retail trade & $\mathrm{BF}$ \\
Security and commodity brokers & $\mathrm{corr}<0$ \\
Services & $\mathrm{BF}$ \\
Telephone and telegraph & $\mathrm{corr}<0$ \\
Transportation & $\mathrm{BF}$ \\
Wholesale trade & $\mathrm{BF}$ \\
\hline
\end{tabular}

Figure 3: List of Increasing Returns to Scale Industries Identified by the Literature Review and the Correlation Coefficient Specification

Source: U.S. Department of Commerce, Bureau of Economic Analysis.

Note 1: $B F$ stands for findings of Basu and Fernald (1997);

Note 2: $A T$ stands for findings of Antweiler and Trefler (2000);

Note 3: corr stands for correlation between total nominal GDP by industry and industry's price deflator. 


\begin{tabular}{|c|c|c|c|c|c|}
\hline \multirow[b]{2}{*}{ Industry } & \multicolumn{3}{|c|}{ labor beta } & \multirow[b]{2}{*}{$\begin{array}{c}\text { labor } \\
\text { shares }\end{array}$} & \multirow{2}{*}{$\begin{array}{c}\% \text { small } \\
\text { firms } \\
1997\end{array}$} \\
\hline & $\begin{array}{l}1947- \\
2001\end{array}$ & $\begin{array}{l}1947- \\
1987\end{array}$ & $\begin{array}{l}\text { 1988- } \\
2001\end{array}$ & & \\
\hline \multicolumn{6}{|l|}{ External IRS } \\
\hline Wholesale trade & 0.06 & 0.06 & 0.03 & 0.05 & 65 \\
\hline Services & 0.44 & 0.36 & 0.53 & 0.22 & 55 \\
\hline Retail Trade & 0.18 & 0.18 & 0.15 & 0.15 & 51 \\
\hline Machinery, except electrical & 0.01 & 0.02 & 0.00 & 0.02 & 47 \\
\hline Electronic equipment and & & & & & \\
\hline instruments & 0.02 & 0.03 & 0.00 & 0.03 & 43 \\
\hline Credit agencies other than banks & 0.01 & 0.01 & 0.01 & 0.00 & 35 \\
\hline Security and commodity brokers & 0.01 & 0.01 & 0.01 & 0.00 & 28 \\
\hline Telephone and telegraph & 0.00 & 0.01 & 0.01 & 0.01 & 10 \\
\hline Average Share of IRS industry & 0.26 & 0.22 & 0.29 & 0.48 & 53 \\
\hline \multicolumn{6}{|l|}{ Traditional } \\
\hline Real estate & 0.02 & 0.02 & 0.01 & 0.01 & 88 \\
\hline Miscellaneous manufacturing & & & & & \\
\hline industries & 0.00 & 0.00 & 0.00 & 0.00 & 67 \\
\hline Lumber and wood products & 0.00 & 0.00 & 0.00 & 0.01 & 64 \\
\hline Furniture and fixtures & 0.00 & 0.00 & 0.00 & 0.01 & 59 \\
\hline Printing and publishing & 0.01 & 0.01 & 0.00 & 0.01 & 51 \\
\hline Leather and leather products & 0.00 & 0.00 & 0.00 & 0.00 & 42 \\
\hline Textile mill products & -0.01 & -0.01 & -0.01 & 0.01 & 31 \\
\hline Apparel and other textile products & -0.01 & 0.00 & -0.02 & 0.01 & 29 \\
\hline Food and kindered products & 0.00 & 0.00 & 0.00 & 0.02 & 28 \\
\hline Paper and allied products & 0.00 & 0.00 & 0.00 & 0.01 & 28 \\
\hline Chemicals and allied products & 0.00 & 0.01 & 0.00 & 0.01 & 21 \\
\hline Average Share of Traditional industry & 0.00 & 0.00 & 0.00 & 0.11 & 48 \\
\hline
\end{tabular}

Figure 4: Employment Volatility in IRS Sectors is Larger than in Traditional Sectors

Source: U.S. Department of Commerce, Bureau of Economic Analysis.

Note 1: Detailed annual series on "Full Time and Part Time Employment by Industry" can be found at: www.bea.gov/bea/dn2/gpo.htm;

Note 2: Percentage of small firms within the industry in 1997 is provided by the U.S. Small Business Administration Office of Advocacy, "US Small Business Indicators 2001." 
for IRS on average are largest in the later period, or in 1987-2001 period. This phenomenon could be explained by our model: as $\sigma \rightarrow 1$, 'labor beta' of the IRS sector becomes larger.

\subsection{The Puzzle of the Jobless Recovery}

We saw that employment in sectors with increasing returns to scale is on the whole more volatile than in other sectors, in the sense of having higher 'labor betas'. We also saw that within the IRS sectors, service sectors have the highest volatility, or highest 'labor betas'. Service sectors employ 22 percent of the U.S. workers (see Figure 4) and are populated by small firms: 55 percent of the firms in the service industry have less than 500 employees. Small firms generate most new jobs in the US, between 60-80 percent between 1989 and 2001, as illustrated in Figure 5 [40], even though they employ only about 50 percent of the workers. According to the numerous studies by the Small Business Administration, 80 percent of industries that generated most employment (during upturns) and lose most employment (during downturns) over the last 10 years have been in service sector [41]. The service sector is key to our study: on the whole it has increasing returns to scale; it generates most jobs; and it is populated by small firms. If IRS industries were a large part of the economy, they should, in principle,

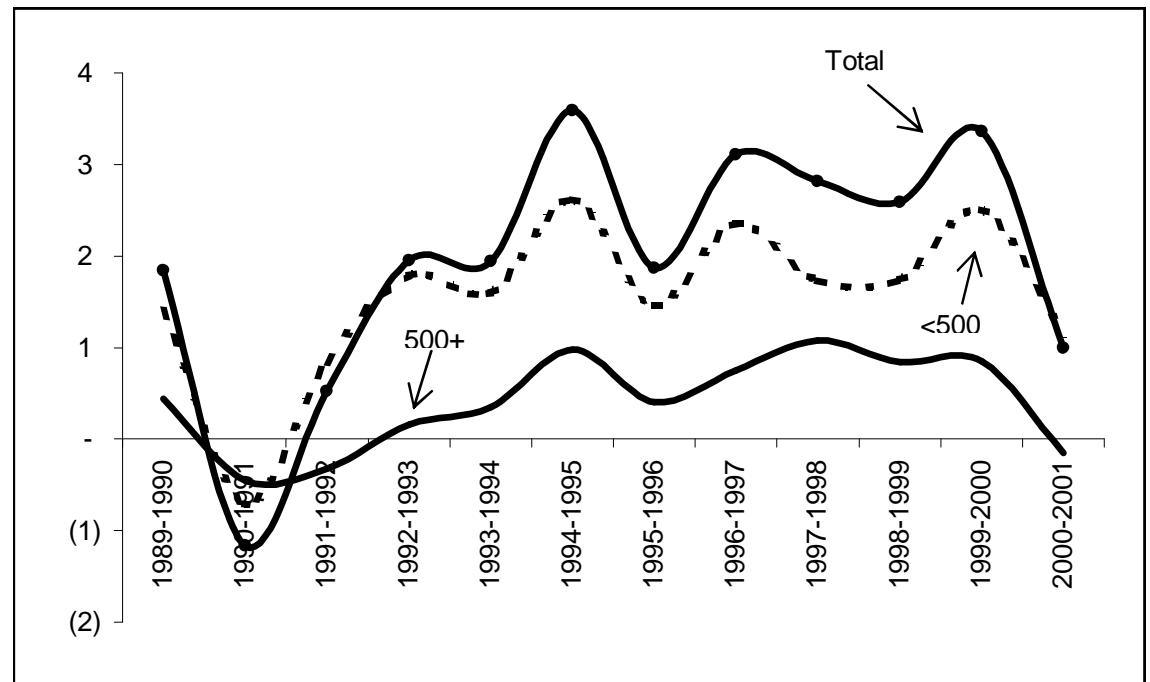

Figure 5: Net Jobs Generated by Firm Size, in millions

Source: Census Bureau, "County Business Patterns Survey".

Note: The data is for January 1989 to March 2004 time period.

generate a large increase in employment during a recovery. The US economy grew 4.1 percent in real terms in the fourth quarter of 2003 (surpassing its lowest point of third quarter of 2001) [37]. Yet employment has not yet reached 
its pre-recession levels. In order for employment to attain its pre-recession levels, 1.5 million jobs lost over 2001-2003 periods $^{27}$ must be replaced [39]. Since the IRS sectors are a significant portion of the economy, they employ around 50 percent of the workers, then we should have job creation rather than the observed jobless recovery. How do we resolve this puzzle? There are at

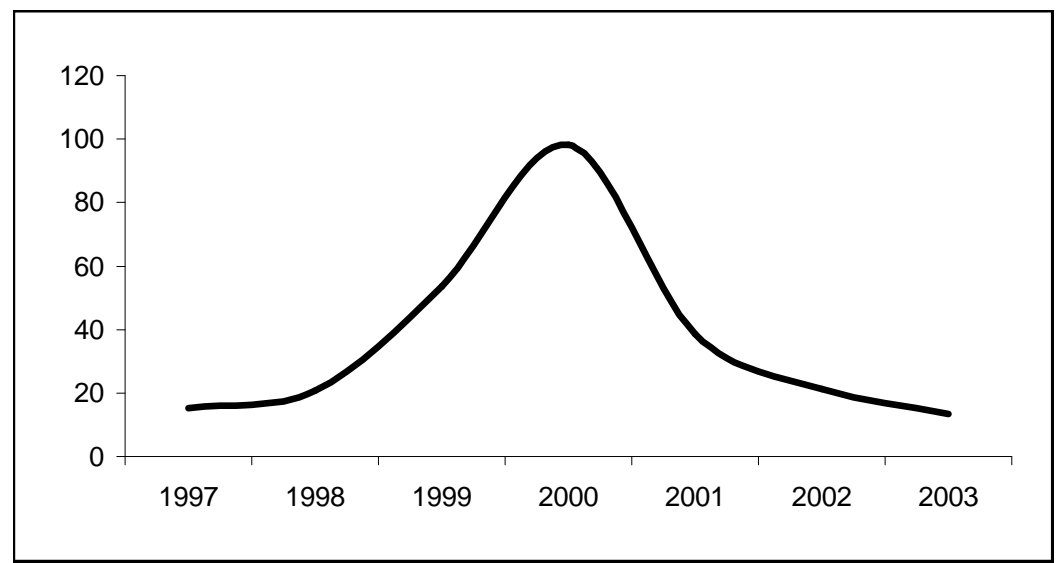

Figure 6: Venture Capital Financing for Small Firms

Source: Small Business Administration Office of Advocacy, SBIC Program Share of Total Venture Capital Financing to Small Business Reported for Calendar Years 1997-September 2003.

least two possible explanations for the jobless recovery: (i) due to the increased uncertainty in the economy (geopolitical and economic), external IRS sectors that are populated by small firms have been particularly badly hit and thus have been unable to generate new employment; and (ii) there has been a structural change in the economy that shifted the 'produced labor' supply curve to the left, making it more difficult to generate new jobs. Both of these situations would lead in our model to a jobless recovery. A combination of these two explanations is at the core of the jobless recovery and is discussed below.

\section{Small Firms and the Service Sector: heightened uncertainty and structural change}

In the current cyclical recovery of 2001-2004, the service sector could have generated most employment, since it has highest 'labor betas' and most new employment comes from this sector [41]. However, the service sector is populated by small firms, which finance their operations through equity and retained earnings rather than debt [42]. Obtaining equity funding or venture capital has been extraordinarily difficult in the environment of high uncertainty ${ }^{28}$ both geopolit-

\footnotetext{
${ }^{27}$ Calculations are done by the authors.

${ }^{28}$ Uncertainty is due to (i) economic and political factors, and (ii) to controversy over corporate practices after one of the worse collapses in history of the stock market.
} 
ical and economic since 2001. Equity funding for small firms, as illustrated by Figure 6, fell 86 percent over three year period, 2000-2003 ${ }^{29}$ [43].

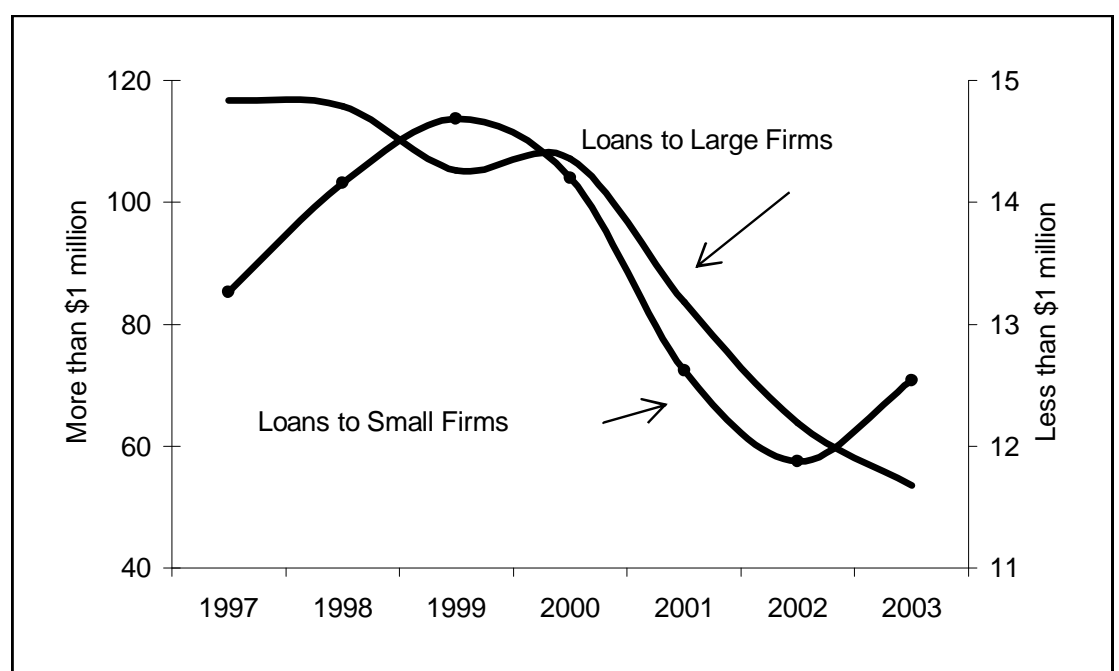

Figure 7: Lending by All U.S. Banks by Size of Loan, in millions of dollars

Source: Federal Reserve Statistical Release, E.2 Survey of Terms of Business Lending: 1. Commercial and industrial loans made by all commercial banks, 1997-2003.

Note: The left hand side axis is for the loans to large firms, i.e. loans that are greater than 1 million dollars; and the right hand side axis is for the loans to small firms, i.e. loans that are less than 1 million dollars.

Figure 7 shows that commercial credit, which constitutes 57 percent of small firms' debt also fell by 17 percent. Left without funds to finance their operations, small firms stumbled during this period and therefore generated fewer jobs. Thus, even though the economy was coming out of a recession, the continued uncertainty, especially felt by the service sector small firms, reduced the likelihood of increased job creation generating conditions associated with a jobless recovery (see Figure 8). The results of our model support also the Federal Reserve Bank of New York's explanation of the jobless recovery [18]. The FRBNY's explanation for the jobless recovery is that a structural change ${ }^{30}$ occurred during the last business cycle. This is supported by their recent study in which the authors show that permanent shifts in the distribution of workers throughout the economy have contributed to the jobless recovery. FRBNY's study proposes three explanations for this change: (i) structural decline might be a reaction to a period of overexpansion, (ii) improved monetary and fiscal

\footnotetext{
${ }^{29}$ Venture capital fell $61 \%$ between 2000 and 2001; 45\% between 2001 and 2002; and 37\% between 2002 and first half of 2003 .

${ }^{30}$ Structural adjustments transform a firm or industry by relocating workers or capital, according to the FRBNY's definition [18].
} 


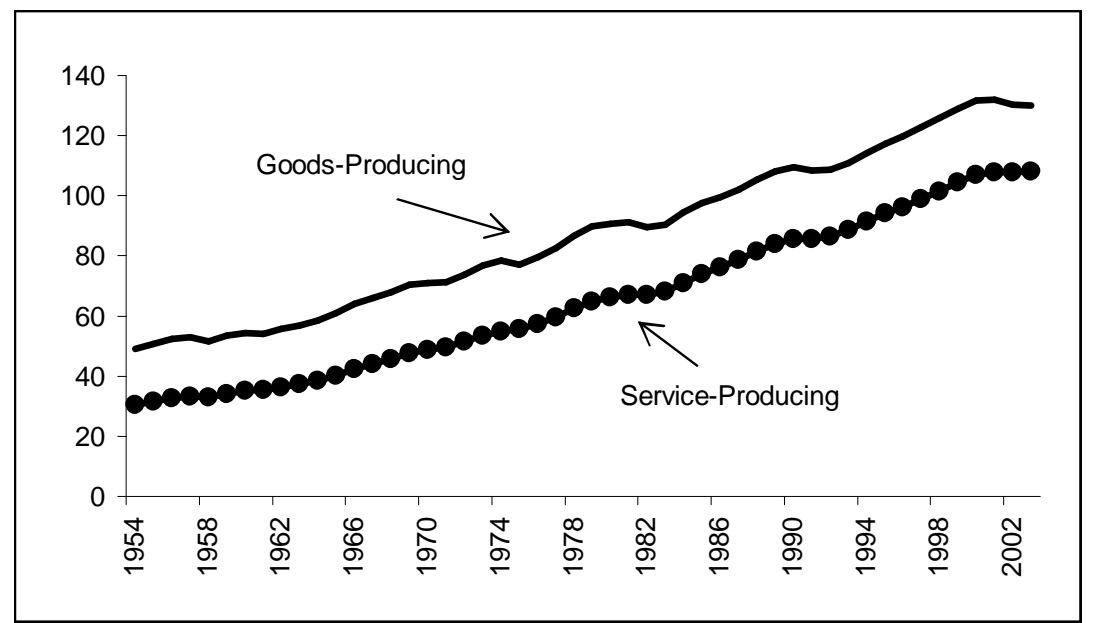

Figure 8: Employment Evolution from 1954 to 2003 in Goods-Producing vs. Service-Providing Industries, in millions Source: U.S. Bureau of Labor Statistics, Establishment Data Survey: "Historical Employment B-1. Employees on Nonfarm Payrolls by Major Industry Sector, 1954 to date."

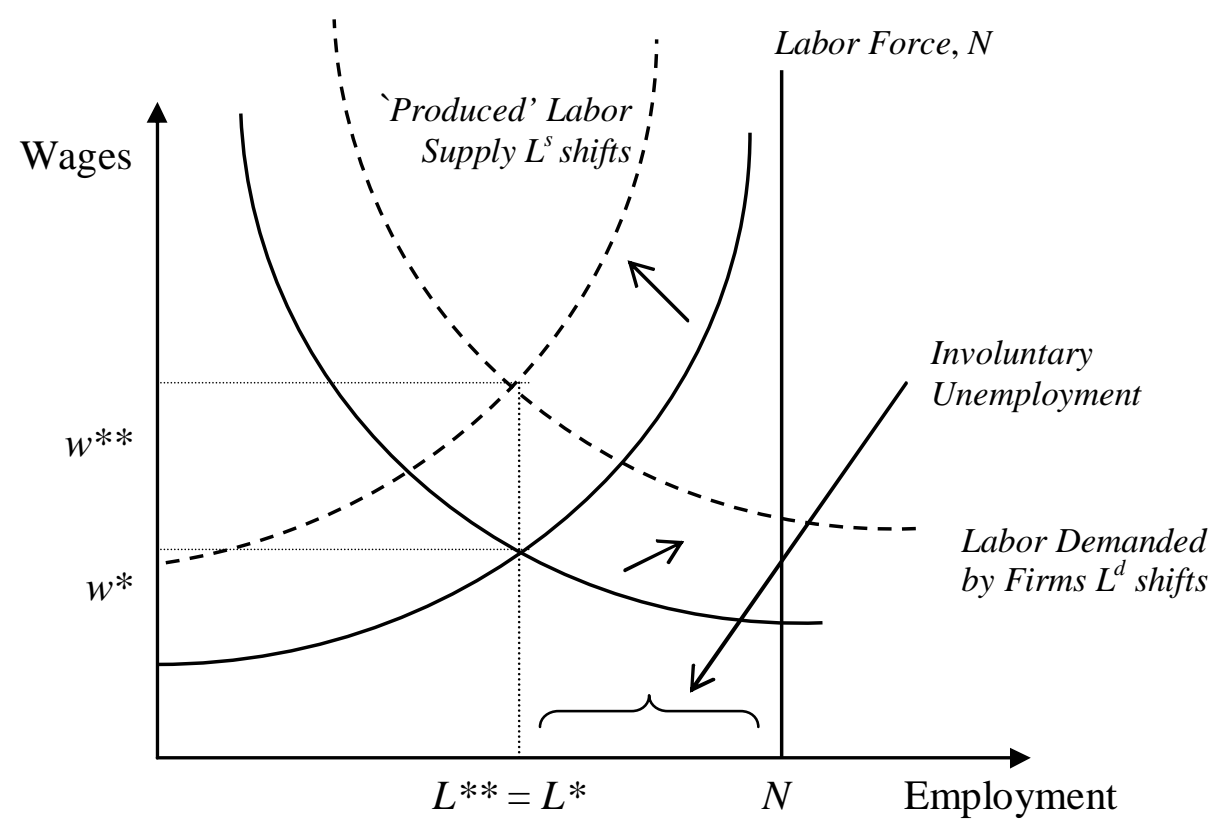

Figure 9: Structural changes shift the Produced Labor supply curve leading to the Jobless Recovery 
policy may have reduced cyclical swings in employment, and (iii) innovation in firm management may be promoting a structural shift towards leaner staffing.

A structural change would require a change in workers' skills. Therefore, even if the recovery created an increased demand for labor as the 'produced' labor function (defined in section 2.03) shifted left, this would have lead to decrease in employment. Figure 9 shows how the new employment level in equilibrium $L^{* *}$ could be even less than the previous level $L^{*}$ with such a shift even with an expansion in labor demand. Our model therefore supports the FRBNY's conclusions.

\subsection{Conclusions and Policies for Job Creation}

We showed that employment volatility is higher in the increasing returns to scale sectors than in the rest of the economy. The highest volatility is observed in the service sector, an increasing returns to scale sector mostly populated by small firms with less than 500 employees. It has been shown elsewhere [12] that smaller firms create most new jobs in the economy. Yet small firms have been deprived of funding during the recovery because of heightened uncertainty, geopolitical and economic. This combination of circumstances could be a reason for the jobless recovery.

Indeed, most of small firms' funding comes from equity financing and venture capital that declined 86 percent over the 2001-2003 period. Even though the current US recovery seems to be standard in terms of real output growth, the dramatically reduced funding undermined the ability of small firms to generate employment. Thus we conclude that the first explanation, (i) in section 5.011, for the jobless recovery seems justified.

A second feature of our model that helps explain a jobless recovery is the impact of structural change on involuntary unemployment. The Federal Reserve Bank of New York has documented that structural change has occurred in this upswing. This could have shifted the 'produced labor' supply to the left making it more difficult for the economy to create new employment, as in (ii) section 5.011 .

The combination of two circumstances (i) the stumbling of small firms, and (ii) structural change, is our preferred explanation for the jobless recovery since 2002.

Several policies can be suggested. Since small firms are viewed as risky, they have limited access to funds, face higher costs of capital, and have less access to top talent. Overcoming these obstacles is what will create most new jobs. Thus, policies should focus on decreasing the risks faced by small firms.

Specific financial policies designed for this purpose were suggested in Chichilnisky [12]. One is to aggregate the equity of smaller firms into 'bundles' that have a lower risk profile due to the 'law of large numbers'. By securitizing these bundles they can be sold in financial institutions - such as stock exchanges - with access to global capital markets. The result is a much larger pool of funds for smaller firms, and lower cost of capital. 
A second proposal is to create credit - enhancement instruments that facilitate the smaller firms' access to capital. A third proposal is to provide access to better borrowing rates for smaller firms by creating large baskets of equity across firms which offer less risk due to diversification - much like Freddie Mae has done successfully in the lower income home mortgage market. Instead of home equity, in this case the assets that back the securities would be the equity in the firms themselves, aggregated throughout many firms in order to reduce risk.

In addition to financial solutions, providing low cost training to employees and benefits to ease sectorial displacements will help resolve problems associated with structural shifts.

\subsection{Appendix}

\section{Workers and the Labor Market (Shapiro and Stiglitz 1984)}

Here we provide a specific formulation of the general equilibrium model with involuntary unemployment following analysis of Shapiro and Stiglitz' in 'Equilibrium Unemployment as a Worker Discipline Device" [32].

There are $N$ identical workers in the economy. All workers dislike putting forth effort, but enjoy consuming goods. Individual's instantaneous utility function can be expressed as $U(c, e)$, assuming for simplicity that the utility function is separable:

$$
U(c, e)=H(c)-\Psi(e)
$$

where $H(c)$ is a continuous function of workers' consumption bundle, such that $\frac{d H}{d c}>0, \frac{d^{2} H}{d c^{2}}<0$; and $\Psi(e)$ is a continuous function of disutility of effort, $e$, such that $\frac{d \Psi}{d e}>0, \frac{d^{2} \Psi}{d e^{2}}<0$.

Each worker maximizes his utility subject to budget constraint:

$$
p_{c} c=w L+r K
$$

where $p_{c}$ is the index of consumer prices and $c$ is the consumption bundle; $w$ stands for wages and $r$ for rental on capital received by each worker.

Assume for simplicity that every employed worker supplies one unit of labor, or $L=1$ and that utility from consumption has a Cobb-Douglas form. Then, worker's problem can be restated as:

$$
\begin{aligned}
\max U(B, I, e) & =B^{\eta} I^{1-\eta}-\Psi(e) \\
\text { s.t. } p_{B} B+I & \leq w+r K
\end{aligned}
$$

where $\eta \in(0,1)$. By solving (1.31), demand functions for goods $B$ and $I$, are given as:

$$
B^{d}=\frac{\eta(w L+r K)}{p_{B}}=B^{d}\left(w, r, p_{B}\right) \text { and } I^{d}=(1-\eta)(w L+r K)=I^{d}\left(w, r, p_{B}\right)
$$


One can also show that (1.31) can be rewritten as an indirect utility function

$$
V(w, r, e)=\theta(w+r K)-\Psi(e)
$$

where $\theta=\left(\frac{\eta}{p_{B}}\right)^{1-\eta}(1-\eta)^{\eta}$.

Each worker is in one of two states: employed or unemployed. There is a positive probability $b$ per unit time that a worker will be separated from his job due to unrelated to his productivity causes (i.e. relocation, bankruptcy, etc. of his enterprise), which is exogenously given. Workers maximize the expected present discounted value of utility with a discount rate $\rho>0$.

$$
W=E \int_{0}^{\infty} V\left(w_{t}, r_{t}, e_{t}\right) e^{-\rho t} d t
$$

The main choice workers make is the selection of the effort or productivity level. If the worker performs well, or at an expected productivity level, i.e. he doesn't shirk, he receives a wage $w$ with probability $(1-b)$. If the worker shirks, there is a probability $q>0$ that he will be caught and fired, and therefore will enter the unemployment pool. While unemployed, he receives unemployment compensation $\bar{w}$ set by the government (and assumed to be zero from now on).

The utility from work of a shirker for a short interval $[0, t]$ can be stated as:

$$
V_{E}^{S}=t\{\theta(w+r K)-\Psi(e)\}+(1-\rho t)\left[(b t+q t) V_{U}+(1-b t)(1-q t) V_{E}^{S}\right]
$$

where $V_{U}$ is the expected lifetime utility of an unemployed individual and $V_{E}^{S}$ is the expected lifetime utility of an employed shirker. $V_{E}^{N}$ is the expected lifetime utility of the employed individual-nonshirker, and can be written as:

$$
V_{E}^{N}=t\{\theta(w+r K)-\Psi(e)\}+(1-\rho t)\left[b t V_{U}+(1-b t) V_{E}^{N}\right]
$$

Solving (1.35) and (1.34) by taking a limit of each of the two equations as $t \rightarrow 0$, rearranging the terms, taking $V_{U}$ as given, and assuming for simplicity that $\Psi(e)$ is a discrete function, such that $\Psi(e)=0$ if the individual shirks, and $\Psi(e)=e>0$ if he doesn't, we get:

$$
\begin{gathered}
\rho V_{E}^{S}=\theta(w+r K)+(b+q)\left[V_{U}-V_{E}^{S}\right] \\
\rho V_{E}^{N}=\theta(w+r K)-e+(b)\left[V_{U}-V_{E}^{N}\right]
\end{gathered}
$$

or

$$
\begin{aligned}
& V_{E}^{S}=\frac{\theta(w+r K)+(b+q) V_{U}}{\rho+b+q} \\
& V_{E}^{N}=\frac{\theta(w+r K)-e+b V_{U}}{\rho+b}
\end{aligned}
$$

The worker will choose to be productive, or to put in $e>0$ if and only if $V_{E}^{N} \geq V_{E}^{S}$ or

$$
w \geq \frac{\rho V_{U}}{\theta}-r K+\frac{e}{q \theta}(q+b+\rho)
$$


Equation (1.39) is known as the No-shirking condition (NSC). In order to determine the wage demanded by the workers, we first have to rewrite NSC explicitly, taking into account the expected utility of an unemployed worker, $V u$. Thus, analogously to equations (1.36), $V u$ can be stated as:

$$
\rho V_{U}=\theta(\bar{w}+r K)+a\left(V_{E}-V_{U}\right)
$$

where $a$ is the job acquisition rate and $V_{E}$ is the expected utility of the employed worker. In equilibrium $V_{E}=V_{E}^{N}$. Now, plugging (1.38) into (1.40) and rearranging the terms, we get:

$$
V_{U}=\frac{\bar{w} \theta(\rho+b)+a \theta w}{\rho(\rho+a+b)}-\frac{a e}{\rho(\rho+a+b)}+\frac{\theta r K}{\rho}
$$

Substituting (1.41) into (1.39), NSC becomes:

$$
w \geq \bar{w}+\frac{e}{\theta}+\frac{e}{q \theta}(\rho+b+a)^{31}
$$

The implication of NSC in this model is that unless there is a penalty from being unemployed (or it takes time before a person can get rehired), there will be no reason for individuals to provide effort ${ }^{32}$. Thus, in order for NSC to be satisfied, there will always be a positive number of unemployed.

The wage demanded by the workers positively depends on the job acquisition rate, $a$. Following the logic of Shapiro-Stiglitz, $a$ can be related to the more fundamental parameters of the model. In steady-state, the flow of workers into the unemployment pool, $b L$ and the flow of workers out of the unemployment pool, $a(N-L)$, (where $L$ is the aggregate employment and $N$ is the total labor force in equilibrium), must be equal:

$$
a(N-L)=b L
$$

Substituting (1.43) into (1.42):

$$
w \geq \bar{w}+\frac{e}{\theta}+\frac{e}{q \theta}\left(\frac{b L}{N-L}+\rho+b\right)
$$

Thus, wage demanded is a negative function of the number of unemployed, and as the number of employed $(L)$ increases, wage demanded increases more than proportionately, because it is affected by two simultaneous factors (i) an increase in the number of employed, and (ii) a decrease in the number of unemployed.

\footnotetext{
${ }^{31}$ Notice that this NSC equation slightly differs from that of Shapiro-Stiglitz. The wage demanded by the workers as in Shapiro-Stiglitz positively depends on the unemployment benefits, effort that the worker puts in, probability of loosing the job $b$, probability of not getting caught shirking $(1-q)$, and the job acquisition rate, $a$. But $w$ depends positively on $p_{B}$, since $\frac{\partial \theta}{\partial p_{B}}=(1-\eta)^{1+\eta}\left(\frac{\eta}{p_{B}}\right)^{-\eta}\left(-\frac{\eta}{p_{B}^{2}}\right)<0$ and $\frac{\partial w}{\partial \theta}=-\frac{e}{\theta^{2}}\left(1+\frac{1}{q}(\rho+b+a)\right)<0$, thus, $\frac{\partial w}{\partial p_{B}}=\frac{\partial w}{\partial \theta} * \frac{\partial \theta}{\partial p_{B}}>0$.

${ }^{32}$ Since NSC can be also stated as $q\left(V_{E}^{S}-V_{U}\right) \geq e$, if an individual could immidiately obtain employment after being fired, or $V_{E}^{S}=V_{U}$, or $a=+\infty$, NSC could never be satisfied.
} 
Rewriting the above expression we get an explicit labor supply equation:

$$
L^{s} \leq N \frac{e q+e \rho+e b-w q \theta}{e q+e \rho-w q \theta}
$$

Or implicitly

$$
L^{s}=L^{s}\left(w, p_{B}, e\right)
$$

such that $\frac{\partial L^{s}}{d w}>0^{33}, \frac{\partial L^{s}}{d p_{B}}<0^{34}$, and $\frac{\partial L^{s}}{d e} \lessgtr 0$ depending on the parameters of the model ${ }^{35}$. Figure 1 illustrates this relationship for a specific effort level $e$ (that could be set to 1 for simplicity).

In equilibrium all markets clear, or:

$$
\begin{aligned}
B^{s *} & =B^{d *}+X_{B}^{*}(B \text { market clears }) \\
I^{s *} & =I^{d *}+X_{I}^{*}(I \text { market clears })
\end{aligned}
$$

where $X_{B}^{*}$ and $X_{I}^{*}$ are equilibrium levels of net exports in $B$ and $I$ sectors respectively. We assume $X_{I}^{*}=0$ and $X_{B}^{*}=0$ but the results are true for any given $X_{I}^{*}$ and $X_{B}^{*}$.

$$
\begin{gathered}
p_{B}^{*} B^{s *}+I^{s *}=w^{*} L^{*}+r^{*} K^{*} \text { (zero profits) } \\
K^{*}=K^{s}=K_{1}^{*}+K_{2}^{*} \text { (capital market clears) } \\
L^{*}=L^{s}=L^{d}=L_{1}^{*}+L_{2}^{*} \text { (labor market clears) }
\end{gathered}
$$

Notice however that labor market clears in the sense that labor supply is equal to labor demand. But since labor supply is given by the NSC (1.44), the labor market is characterized by the existence of involuntary unemployment, due to $N>L^{*}$, as demonstrated by Figure 2. Workers without a job are willing to work at a wage below $w^{*}$ but cannot make a credible promise not to shirk at such a wage ${ }^{36}$, and thus cannot be hired by the firms.

We can characterize labor market equilibrium in a more explicit way. Since the wage paid by each firm must satisfy the NSC (1.44), wages paid by firms given by (1.10) can be rewritten as:

$$
\frac{e}{\theta}+\frac{e}{q \theta}\left(\frac{b L^{*}}{N-L^{*}}+\rho+b\right)=\alpha e^{A(\alpha-1)} p_{B}^{\frac{\beta-1}{\beta-\alpha}}
$$

\footnotetext{
${ }^{33}$ Since $\frac{\partial\left(L^{s}\right)}{\partial w}=q \theta N e \frac{b}{(e q+e \rho-w q \theta)^{2}}>0$.

${ }^{34}$ Since $\frac{\partial L^{s}}{\partial \theta}=w q N e \frac{b}{(e q+e \rho-w q \theta)^{2}}>0$ and $\frac{\partial \theta}{\partial p_{B}}=(1-a)^{1+a}\left(\frac{a}{p_{B}}\right)^{-a}\left(-\frac{a}{p_{B}^{2}}\right)<0$, then $\frac{\partial L^{s}}{\partial p_{B}}=\frac{\partial L^{s}}{\partial \theta} * \frac{\partial \theta}{\partial p_{B}}<0$

${ }^{35}$ Since $\frac{\partial\left(L^{s}\right)}{\partial e}=N \frac{e q+e \rho+e b-w q \theta}{(e q+e \rho-w q \theta) e}=\frac{N}{e q+e \rho-w q \theta} q+\frac{N}{e q+e \rho-w q \theta} \rho+\frac{N}{e q+e \rho-w q \theta} b-$ $\frac{N}{(e q+e \rho-w q \theta) e} w q \theta$.

${ }^{36}$ As pointed out by Shapiro-Stiglitz, the unemployment in this model is different from that characterized by the search unemployment. Here, all workers and all firms are identical. There is perfect information about job availability but firms are assumed unable to perfectly and costlessly observe the work effort applied by their employees.
} 
Solving the above expression and taking for simplicity $e=1$ when workers exert effort, gives us the total labor used in the economy in equilibrium $L^{*}$ as a function of a single unknown parameter $p_{B}$ :

$$
L^{*}=N \frac{\left\{\alpha e^{A(\alpha-1)} p_{B}^{\frac{\beta-1}{\beta-\alpha}}-\frac{1}{\theta}\right\} q \theta-\rho-b}{\left\{\alpha e^{A(\alpha-1)} p_{B}^{\frac{\beta-1}{\beta-\alpha}}-\frac{1}{\theta}\right\} q \theta-\rho}=L^{*}\left(p_{B}\right)
$$

The rest of the solution of this general equilibrium model follows the main text, writing explicitly the 'resolving' equation for the model:

$$
F\left(p_{B}=I^{d *}-\left\{\begin{array}{l}
\left\{L^{*}-\frac{e^{A} L^{*}}{\left(e^{A}-e^{B}\right)}-\frac{e^{A} e^{B} K^{s} p_{B}^{\frac{1}{\beta-\alpha}}}{\left(e^{A}-e^{B}\right)}\right\}^{\frac{\beta}{1-\sigma}} \\
*\left\{K^{s}-\frac{L^{*} p_{B}^{\frac{1}{\alpha-\beta}}}{\left(e^{A}-e^{B}\right)}-\frac{e^{B} K^{s}}{\left(e^{A}-e^{B}\right)}\right\}^{\frac{1-\beta}{1-\sigma}}
\end{array}\right\}=0\right.
$$

where from (1.10) and (1.12), $I^{d *}\left(p_{B}\right)$ is a function of $p_{B}$ alone:

$$
I^{d *}\left(p_{B}\right)=(1-\eta)\left\{\left(\alpha e^{A(\alpha-1)} p_{B}^{\frac{\beta-1}{\beta-\alpha}} L^{*}\left(p_{B}\right)+(1-\alpha) e^{A \alpha} p_{B}^{\frac{\beta}{\beta-\alpha}} K^{*}\right)\right\}
$$

Solving the equation $F\left(p_{B}\right)=0$, gives an equilibrium value of $p_{B}^{*}$ from which all equilibrium values of other variables $\left(K_{1}^{*}, K_{2}^{*} L_{1}^{*} L_{2}^{*}, w^{*}, r^{*}, B^{s *}, I^{s *}, B^{d *}, I^{d *}\right.$, $\left.\gamma^{*}\right)$ can be computed. The model is thus solved. 


\section{Bibliography}

[1] Werner Antweiler; Daniel Trefler, "Increasing Returns and All That: A View From Trade". NBER Working Papers \#7941, Oct. 2000.

[2] Kenneth Arrow, "The Economic Implications of Learning by Doing". Review of Economic Studies, 1962, Vol. 29, No. 3, pp. 155-173.

[3] Susanto Basu; John G. Fernald, "Aggregate Productivity and the Productivity of Aggregates". NBER Working Papers \#5382, Dec. 1995.

[4] Susanto Basu; John G. Fernald, "Returns to Scale in U.S. Production: Estimates and Implications". The Journal of Political Economy, Apr., 1997, Vol. 105, No. 2., pp. 249-283.

[5] Elise S. Brezis; Paul R. Krugman; Daniel Tsiddon, "Leapfrogging in International Competition: A Theory of Cycles in National Technological Leadership". The American Economic Review, Dec., 1993, Vol. 83, No. 5., pp. 1211-1219.

[6] Craig Burnside, "Production Function Regressions, Returns to Scale, and Externalities". Journal of Monetary Economics, 1996, Vol. 37, pp. 177-201.

[7] David Cass and Herakles Polemarchakis, "Convexity and Sunspots: A Remark", Journal of Economic Theory, Dec. 1990, Vol. 52, pp. 433-439.

[8] Census Bureau, "County Business Patterns Survey", provided by Virginia University at http://fisher.lib.virginia.edu/collections/stats/cbp/

[9] Graciela Chichilnisky, "Traditional Comparative Advantages vs. Economies of Scale: NAFTA and GATT". Rivista Di Politica Economica, Apr. 1993, pp. 161-197.

[10] Graciela Chichilnisky, "Traditional Comparative Advantage vs. Increasing Returns to Scale: NAFTA and the GATT," International Problems of Economic Interdependence, New York, 1994 (eds. Baldassarri, M., Di Matteo, M., and Mundell R.), St. Martin's Press Inc., pp. 161-197. 
[11] Graciela Chichilnisky, "Trade Regimes and GATT: Resource Intensive vs. Knowledge Intensive growth" Chapter 10 in Levi-Livermore,A. (ed.) Handbook on the Globalization of the World Economy, Chapter 10, pp. 226-249, Edward Elgar, Cheltenham UK. Northhampton, Mausa, 1998, pp. 147-181.

[12] Graciela Chichilnisky, "The Job Creating Machine.", Columbia University, Department of Economics Discussion Paper Series, No. 0304-17, May 2004.

[13] Graciela Chichilnisky and Olga Gorbachev, "Volatility in the Knowledge Economy", Economic Theory, Sept. 2004 (forthcoming).

[14] Graciela Chichilnisky and Geoffrey Heal, The Evolving International Economy. Cambridge University Press, 1986.

[15] Graciela Chichilnisky, A. Beltratti, and Geoffrey M. Heal, "Sustainable Use of Renewable Resources," (with A. Beltratti and G.M. Heal), Chapter 2.1, Sustainability: Dynamics and Uncertainty. (G. Chichilnisky, G.M. Heal, and A.Vercelli, eds), Kluwer Academic Publishers, The Netherlands, 1998, pp. $49-76$.

[16] John S. Chipman, "External Economies of Scale and Competitive Equilibrium", The Quarterly Journal of Economics, Aug. 1970, Vol. 84, No. 3, pp. 347-385.

[17] Federal Reserve Board of Governors, "Statistical Release. E.2 Survey of Terms of Business Lending: 1. Commercial and industrial loans made by all commercial banks", 1997-2003.

[18] Erica L Groshen and Simon Potter, "Has Structural Change Contributed to a Jobless Recovery?" Current Issues in Economics and Finance, Vol. 9, No. 8, Aug. 2003.

[19] Geoffrey M. Heal, ed., The Economics of Increasing Returns. Edward Elgar, 1999.

[20] Geoffrey M. Heal, "Macrodynamics and Returns to Scale". The Economic Journal, Mar. 1986, Vol. 96, Is. 381, pp. 191-198.

[21] Dale W. Jorgenson, "Productivity and Postwar U.S. Economic Growth". The Journal of Economic Perspectives, Vol. 2, Iss.4, (Autumn, 1988), pp. $23-41$.

[22] Dale W. Jorgenson, Mun S. Ho, and Kevin J. Stiroh, "Projecting Productivity Growth: Lessons from the U.S. Growth Resurgence". Economic Review, 2002, Iss.Q3, pp. 1-13.

[23] Paul Krugman, "Scale Economies, Product Differentiation, and the Pattern of Trade". The American Economic Review, Dec., 1980, Vol. 70, No. 5., pp. 950-959. 
[24] Paul Krugman, "Intraindustry Specialization and the Gains from Trade". The Journal of Political Economy, Oct., 1981, Vol. 89, No. 5., pp. 959-973.

[25] Paul Krugman, "New Theories of Trade Among Industrial Countries (in International Trade)". The American Economic Review, May, 1983, Vol. 73, No. 2, Papers and Proceedings of the Ninety-Fifth Annual Meeting of the American Economic Association. pp. 343-347.

[26] Paul Krugman, "Increasing Returns and Economic Geography". The Journal of Political Economy, Jun. 1991, Vol. 99, No. 3, pp. 483-499.

[27] Arvind Panagariya, "Variable Returns to Scale in Production and Patterns of Specialization". The American Economic Review, Mar. 1981, Vol. 71, Is. 1, pp. 221-230.

[28] Catherine J. Morrison Paul and Donald S. Siegel, "Scale Economies and Industry Agglomeration Externalities: A Dynamic Cost Function Approach", The American Economic Review, Vol. 89, No.1, (Mar. 1999), pp. 272-290.

[29] Luis A. Rivera-Batiz, Paul Romer, "Economic Integration and Endogenous Growth". The Quarterly Journal of Economics, May 1991, Vol. 106, Is. 2, pp. 531-555.

[30] Paul Romer, "Increasing Returns and Long Run Growth". Journal of Political Economy, 1986, Vol. 94, No. 5, pp. 1002-1037.

[31] Stephanie Schmitt-Grohé, "Endogenous Business Cycles and the Dynamics of Output, Hours, and Consumption". The American Economic Review, Dec. 2000, Vol. 90, No. 5, pp. 1136-1159.

[32] Carl Shapiro, Joseph E. Stiglitz, "Equilibrium Unemployment as a Worker Discipline Device", The American Economic Review 74, Is.3, June 1984, pp. $433-444$.

[33] Jerome Stein, The Economics of Future Markets, 1987, New York: Basil Blackwell.

[34] U.S. Department of Commerce, Bureau of Economic Analysis: Survey of Current Business, May 2003.

[35] U.S. Department of Commerce, Bureau of Economic Analysis: Survey of Current Business, Nov. 2002.

[36] U.S. Department of Commerce, Bureau of Economic Analysis: Survey of Current Business, "Improved Estimates of Gross Product by Industry for 1947-1998", June 2000.

[37] U.S. Department of Commerce, Bureau of Economic Analysis, "News Release: Gross Domestic Product and Corporate Profits", March 25, 2004. 
[38] U.S. Department of Commerce, Bureau of Economic Analysis: Survey of Current Business, May 1997.

[39] U.S. Department of Labor, Bureau of Labor Statistics, data.bls.gov/ servlet/SurveyOutputServlet.

[40] U.S. Small Business Administration Office of Advocacy "Small Business by the Numbers", www.sba.gov/advo/ December 2003.

[41] U.S. Small Business Administration Office of Advocacy, "US Small Business Indicators," 1995-2002.

[42] U.S. Small Business Administration Office of Advocacy, "Financing Patterns of Small Firms: Findings from the 1998 Survey of Small Business Finance.", Sept. 2003.

[43] Venture One, "Annual financing survey by Venture One of San Francisco," web at www.ventureone.com. 